\title{
O COMBATE À FOME E AO DESPERDÍCIO DE ALIMENTOS NA REGIÃO NORDESTE
}

\author{
RAQUEL MIRANDA CANOSO
}

\begin{abstract}
RESUMO
Este artigo analisa a relação entre a má distribuição e a dificuldade no acesso aos alimentos e os níveis de desperdício e fome no Nordeste, tendo como objetivo principal o debate sobre os motivos que levam inúmeras famílias a passarem fome enquanto a oferta de alimentos cobriria a demanda. Para a realização dessa pesquisa monográfica utilizou-se o método explicativo no qual foi utilizado teorias malthusianas como as expostas por Thomas Robert Malthus e David Ricardo e análises contrárias a esse pensamento como as apresentadas nos relatórios da FAO. Dados fornecidos pelo censo do IBGE de 2013 foram utilizados para o levantamento dos dados de populações com insegurança alimentar no Nordeste, assim como os dados fornecidos pela pesquisa de 2018 da Embrapa sobre o desperdício no território brasileiro. Entretanto, os dados colhidos sobre o desperdício de alimentos na região nordeste não foram suficientes para realizar uma conexão com os índices de fome, sendo essa mais atrelada a estrutura do sistema agrário capitalista.
\end{abstract}

PALAVRAS-CHAVE: alimentos; desperdício; fome; agroalimentar; nordeste.

\begin{abstract}
Analyze the relationship between bad distribution and the difficulty in accessing food and the levels of waste and hunger in the Northeast, with the main objective of the debate on the reasons that lead countless families to go hungry while the supply of food would cover the demand. In order to carry out this monographic research, the explanatory method was used, in which Malthusian theories were used, such as those exposed by Thomas Robert Malthus and David Ricardo, and analyzes contrary to this thought, as presented in FAO reports. Data provided by the 2013 IBGE census were used to survey data on populations with food insecurity in the Northeast, as well as data provided by Embrapa's 2018 survey on waste in Brazilian territory. However, the data collected on food waste in the northeastern region were not sufficient to make a connection with hunger rates, which is more closely linked to the structure of the capitalist agrarian system.
\end{abstract}

KEY WORDS: food; waste; hunger; agrifood; northeast.

\footnotetext{
${ }^{1}$ Universidade Federal do ABC. E-mail: raquelmcanoso@hotmail.com
} 


\section{INTRODUÇÃO}

A má distribuição de alimentos e a fome são dois problemas intrinsecamente ligados e que afetam o mundo inteiro, ao mesmo tempo que milhões de toneladas de alimentos são desperdiçadas anualmente. No Brasil a realidade não é diferente. Usando como análise a região do país que mais sofre com a fome, o Nordeste, por que ainda é observado um alto nível de desperdício de alimentos? Teorias como a malthusiana, proposta por Thomas Robert Malthus no século XVIII, defendem a ideia de que a população mundial cresce em um ritmo mais acelerado do que a produção de alimentos; a primeira seguiria um crescimento em progressão geométrica enquanto a segunda seguiria em progressão aritmética, logo, o combate à fome seria impossível, e sempre haveriadiferentes regiões em que a fome predominaria. Entretanto, relatórios apresentados pela Organização das Nações Unidas para a Alimentação e a Agricultura (FAO) (2018) defendem a teoria de que o problema da fome ainda enfrentado no século XXI provém de uma questão estrutural, ou seja, da má distribuição de alimentos e não da falta deles em si. O desperdício encontrado principalmente em regiões urbanas, onde o acesso a produtos industrializados e redes de fast-food é facilitado, reafirmaria a teoria de que a dificuldade do acesso aos alimentos seria um dos principais fatores da perpetuação da fome e não a falta deles em si.

É possível observar a partir dos diferentes regimes alimentares quea sociedade capitalista enfrentou que a produção de alimentos sempre esteve com um crescimento muito acelerado, deixando de lado questões ambientais e/ou sociais. Foi gerado um maior acesso a alimentos baratos, mas não necessariamente saudáveis (alimentos processados) atrelado ao aumento dos níveis de desperdício de alimentos principalmente em regiões urbanas. Entretanto, esse acesso não foi efetivado em todas as regiões, como observado no Nordeste brasileiro, no qual os níveis de desnutrição são preocupantes. Novamente a questão da distribuição é posta em pauta, com regiões tendo a possibilidade de desperdiçar enquanto outras ainda possuem famílias vivendo em fome extrema.

A importância desse estudo se dá pela dura realidade enfrentada por diversas famílias que lutam para ter suas refeições diárias, enquanto o atual sistema perpetua o privilégio da maximização dos lucros de grandes empresas agrícolas em vez da segurança alimentar, associado com a normalização do desperdício de alimentos que reafirma a noção de desigualdade, já que a oferta de alimentos cobriria a demanda. 


\section{CRISE AGROALIMENTAR E A FOME}

O combate à fome é uma realidade enfrentada durante toda a história, desde a fixação das sociedades nômades com a agricultura até o investimento em tecnologias de transgênicos nas plantações. Diferentes autores tentaram analisar quais os desafios seriam enfrentados para a diminuição da fome, sendo um deles Thomas Robert Malthus, precursor da teoria malthusiana em sua obra Ensaio sobre o Princípio da População (1798). O autor pretende explicar a natureza e a origem da pobreza como sendo um produto do comportamento daqueles que nela vivem, queseriam os responsáveis por manterem o ciclo de subdesenvolvimento. Tal pensamento confrontava as ideias de progresso inicialmente presentes com a Revolução Francesa, defendendo que as tentativas de melhorar as condições de vida dos mais pobres tenderiam a uma piora da situação, já que estes seriam incentivados a terem mais filhos e consequente mais pessoas demandariam alimentos. Logo, o ritmo de crescimento da população seria mais acelerado do que o aumento da produção de alimentos; a primeira seguiria um crescimento em progressão geométrica enquanto a segunda seguiria em progressão aritmética, mantendo a fome como um mecanismo natural e inevitável.

David Ricardo, um autor de extrema importância no âmbito econômico, foi responsável pela elaboração da teoria da Renda da Terra (1815) na qual faz uma interligação entre o preço dos cereais e a repartição da renda, o aumento da população, o preço da renda da terra, as vantagens recíprocas do comércio internacional e o nível de salário de subsistência dos trabalhadores. Segundo o autor, o lucro industrial está diretamente ligado ao valor da renda da terra e aos salários dos trabalhadores. Os salários seriam determinados pela quantidade de mão de obra disponível e o custo de vida no nível de subsistência, ou seja, os salários não poderiam cair a um nível em que os trabalhadores não pudessem se manter, pois isso prejudicaria sua reprodução e consequentemente a oferta de mão de obra no mercado. A renda da terra, por sua vez, seria determinada pelo nível de fertilidade e localização das terras e pelos custos e equalização dos preços dos produtos agrícolas. Quanto mais perto as terras estivessem dos centros de comercialização e quanto mais férteis fossem, maiores seriam os lucros (LENZ, 1985).

A influência do aumento da população entra em questão quando é necessário o uso de terras mais distantes e menos férteis para a produção de alimentos. O trabalho e o custo nessas terras eram maiores fazendo com que os preços desses produtos crescessem, logo, os salários dos trabalhadores precisavam ser maiores para que estes pudessem se manter, diminuindo os lucros das indústrias. O resultado desse fenômeno seria a transferência do capital das mãos da indústria e dos trabalhadores para os proprietários fundiários gerando um estado estacionário na economia capitalista. Esse cenário manteria a fome entre as classes mais pobres, já que cada vez mais é necessário o uso de terras, sendo que estas se tornam menos produtivas com o tempo. 
O imperativo do século XIX ronda o aumento da produção, já que o fim da fome estaria diretamente ligado com a quantidade de alimentos produzidos e ela só se manteria devido às barreiras físicas que impedem seu crescimento. Esse pensamento sofreu uma mudança após a Revolução Verde na década de 1940 na qual houve uma sequência de grandes investimentos em tecnologia agrícola como sementes manipuladas em laboratório, fertilização do solo, pesticidas, herbicidas e maquinário que possuíam o objetivo de aumentar a produtividade. Tratava-se de uma política de desenvolvimento dos EUA após o final da Segunda Guerra Mundial que focava garantir a prosperidade econômica das elites estadunidenses e não necessariamente promover uma segurança alimentar às populações mais pobres dos países em desenvolvimento, como era divulgado nas propagandas políticas. A Revolução Verde representou uma ligação implícita com as relações capitalistas de produção, sendo companhias como a Rockefeller primordiais nesse processo (SHUTTER, 2014).

A Revolução Verde conseguiu gerar um aumento da produção de alimentos significativo, mas gerougrandes consequências como o aumento da monocultura latifundiária que prejudicou inúmeros pequenos produtores que não tinham a capacidade de atingir os mesmo níveis de produção e acabavam se endividando após empréstimos bancários com o objetivo de investimento em maquinário tendo como única forma de quitação da dívida a venda das propriedades para os grandes produtores. As monoculturas também foram um epicentro do aumento das pragas nas plantações provocado pelo intenso uso de fertilizantes e a falta de variedade de espécies, gerando uma dependência dos pesticidas e herbicidas para o combate do problema (ROSS, 2000).

As mudanças para o novo processo produtivo agrário possuiu como beneficiadora a indústria petrolífera, pois o petróleo é um insumo básico para a produção dos fertilizantes e agrotóxicos utilizados nas plantações, associado ao combustível necessário para o transporte desses produtos, seja ele dentro do território continental (caminhões e trens) como fora dele (navios). Consequentemente houve uma associação do preço do petróleo com o dos alimentos, uma relação antes inexistente. A relação entre a indústria petrolífera e a latifundiária gerou uma dependência dos países periféricos tanto para compra de sementes que foram geneticamente modificadas, e com isso possuem maior produtividade e resistência, mas são incapazes de se reproduzirem, como fertilizantes e agrotóxicos.

O fim da Segunda Guerra Mundial foi também acompanhado da criação da Organização para a Alimentação e Agricultura (FAO) em 1945, uma agência especializada das Nações Unidas que possui o objetivo de erradicar a fome no mundo trazendo segurança alimentar a todos. A FAO foi responsável pela realização de inúmeros relatórios sobre a questão da fome em diferentes países e teverelatores como Olivier de Shutter, de grande importância para a disseminação de um novo 
pensamento sobre a fome. Em seu relatório à ONU,Direito à Alimentação (2014, p. 3), Shutter introduz seu trabalho analisando o significado do direito à alimentação no qual:

O direito à alimentação é o direito de todo indivíduo, sozinho ou em comunidade com os outros, ter sempre acesso físico e econômico a meios suficientes, adequados e culturalmente aceitáveis, produzidos e consumidos de maneira sustentável, preservando o acesso aos alimentos para gerações futuras. Os indivíduos podem garantir o acesso aos alimentos (a) obtendo renda de emprego ou trabalho independente; (b) através de transferências sociais; ou (c) produzindo sua própria comida, para aqueles tem acesso à terra e outros recursos produtivos (SHUTTER, 2014, p. 3).

Segundo o autor, a manutenção da fome seria uma questão estrutural do mercado e não uma falta de produtos em si. As agências da ONU estimaram, a partir de um novo método para calcular a subnutrição implantado em 2012, que a fome extrema diminuiu globalmente de mais de 1 bilhão de pessoas entre 1990 e 1992 para 842 milhões entre 2011 e 2013, uma queda na representação de $18,9 \%$ da população mundial para $12 \%$ (Shutter, 2014). A subnutrição não está necessariamente restrita à quantidade de calorias ingeridas, mas sim aos nutrientes consumidos, ou seja, o seu combate não significa apenas o fornecimento de qualquer alimento às populações, mas sim alimentos adequados. Dietas inadequadas são um dos principais fatores que contribuem para o aumento de doenças não transmissíveis, como aquelas relacionadas à obesidade, diabetes tipo 2 , doenças cardíacas ou câncer gastrointestinal. Em 2008, 1,4 bilhão de adultos estavam acima do peso, incluindo 400 milhões de obesos, dados estes que representam o dobro daqueles coletados em 1980 (SHUTTER, 2014).

Outro fator de preocupação para Shutter é a questão da produção de proteína animal. A tendência é que o aumento da renda de populações mais pobres gere um aumento no consumo de carne. Um estudo realizado pela FAO, High-level Expert Forum on How to Feed the World in 2050, estimou que para que a demanda projetada para 2050 fosse atingida, 470 milhões de toneladas de carne deveriam ser produzidas, um aumento de cerca de 200 milhões de toneladas em comparação com os níveis de 2005-2007 (FAO, 2009, p. 8). Esses dados refletem uma insustentabilidade do sistema. Para que a produção de carne se realize uma enorme quantidade de cereais para ração são demandados, direcionando cerca de mais de um terço da produção desse insumo para a pecuária. Se as projeções para 2050 se mantiverem, será necessário que mais de $50 \%$ do plantio de cereais seja direcionada para a produção de ração, o que demandaria uma quantidade de espaço cultivável muito grande (SHUTTER, 2014, p. 6). O consumo de carne desvia os alimentos das populações mais pobres que não possuem capital para comprar a proteína animal e ficam restritas ao consumo de cereais, que produzidos em escala industrial são utilizados para alimentação de animais e não de pessoas, ou seja, a manutenção desse sistema produtivo fomenta a utilização de espaços e insumos para o consumo de carne e agrava a pobreza e a degradação ambiental. 
É observado que o sistema agroalimentar capitalista almeja a maximização dos lucros, focando em grandes volumes de mercadorias, mas não na sua distribuição. A manutenção da pobreza é aceita quando impulsiona os ganhos de uma pequena parcela da população. Contrariando as teorias malthusianas de que a população cresce em um ritmo mais acelerado do que a produção de alimentos, entre 1960 e 2000 foi constatado pela FAO que a produção superou em muito o crescimento da população, entretanto, essa produção não foi necessariamente voltada para a melhoria da segurança alimentar. Apenas produtos agrícolas específicos possuíram crescimento, principalmente aqueles relacionados à produção de carne. As políticas e tecnologias associadas a esse ritmo de produção estão restritas a grandes proprietários de terras em detrimento de pequenos produtores, resultando no aumento da desigualdade nas áreas rurais e na marginalização das causas da pobreza. Se o capital investido nos latifúndios fossem voltados para o desenvolvimento da segurança alimentar, a fome conseguiria finalmente ser superada, entretanto, a maximização dos lucros detém prioridade.

\section{O DESPERDÍCIO DE ALIMENTOS}

Mesmo a fome sendo uma das realidades ainda a serem superadas no século XXI, o desperdício de alimentos faz parte da sociedade capitalista, uma sociedade na qual a desigualdade prevalece e o consumo é cada vez mais incentivado. As pessoas não consomem mais alimentos apenas para satisfazerem uma necessidade básica, mas sim como um prazer estimulado todos os dias pela sociedade. Fast-foods fazem parte do cotidiano urbano, comidas enlatadas, congeladas, todas aquelas produzidas industrialmente semeiam a facilidade em consumir de uma forma prática, mas não necessariamente saudável.

Há uma diferenciação entre perda de alimentos e desperdício de alimentos. O primeiro ocorre nos estágio de produção, pós-colheita, processamento e até mesmo transporte do produto, não envolve uma ação consciente e proposital, enquanto o segundo está vinculado ao varejo e consumo final, ou seja, depende do comportamento dos vendedores e consumidores (PARFITT et al., 2010). A análise desse desperdício é feita apenas em produtos direcionados para consumo humano, excluindo aqueles voltados para alimentação de animais e partes do produto que não são comestíveis, ou seja, levam em consideração apenas produtos comestíveis destinados ao consumo humano (FAO, 2011).

É possível distinguir em cinco categorias o desperdício/perda de alimentos tanto vegetais quanto animais. Dentro da categoria vegetal estão a produção agrícola com perdas devido a danos mecânicos e/ou durante a colheita; manuseio e armazenamento pós-colheita, devido à perda e degradação durante o manuseio, armazenamento e transporte do produto, entre a fazenda e seus 
distribuidores; processamento, envolvendo derramamento e degradação durante o processamento industrial ou doméstico como na produção de sucos, conservas e panificação; distribuição, relacionada ao sistema de mercado entre eles atacadistas, supermercados, varejistas e feiras; e por fim o consumo no nível da família. No âmbito animal, o desperdício no primeiro nível ocorre com a carne bovina, suína e de aves na perda destes animais antes do abate ou na sua tentativa de reprodução, com peixes durante perdas na pesca e com o leite se refere a diminuição da produção devido à doença da vaca leiteira (mastite). Assim como com vegetais, o produto de origem animal sofre perdas nos processos industriais, transportes, comercialização e no consumo final das famílias (FAO, 2011).

Uma pesquisa realizada pela Empresa Brasileira de pesquisa Agropecuária (Embrapa) sobre o desperdício de alimentos no Brasil demonstrou que:

As famílias brasileiras desperdiçam, em média, 353 gramas de comida por dia ou $128,8 \mathrm{~kg}$ por ano. Em análise per capita, o desperdício é de 114 gramas diários, representando um desperdício anual de $41,6 \mathrm{~kg}$ por pessoa. O ranking dos alimentos mais desperdiçados mostra arroz $(22 \%)$, carne bovina $(20 \%)$, feijão $(16 \%)$ e frango $(15 \%)$ com os maiores percentuais relativos ao total desperdiçado pela amostra pesquisada. Hortaliças (4\%) e Frutas (4\%) são desperdiçados em menor quantidade relativa ao volume total (EMBRAPA, 2018, p. 14).

Essa mesma pesquisa observou que consumidores com maior consciência ambiental e acesso a informações sobre o impacto do desperdício no orçamento familiar tendem a desperdiçar menos alimentos. Um dado que chama a atenção foi a constatação da não relação entre variáveis demográficas como renda e idade no nível de desperdício, mas sim os comportamentos alimentares que determinadas famílias adotam. A variável com maior influência foi a da valorização da fartura, influenciando nos níveis de desperdício desde a compra até o preparo do alimento. A única categoria de alimentos que sofreu influência da renda familiar foi a das hortaliças, as classes A e B tendem a desperdiçar mais nesse quesito por se tratar de alimentos mais caros, enquanto as classes de menor renda tendem a consumir menos desses alimentos.

É possível observar na Figura 1 os principais antecedentes do desperdício a partir de famílias de classe média baixa. Muitas dessas famílias possuem o objetivo de diminuírem seus gastos, mas que a partir de estratégias errôneas acabam não tendo resultado. 
Figura 1 - Itinerário do desperdício de alimentos em famílias brasileiras

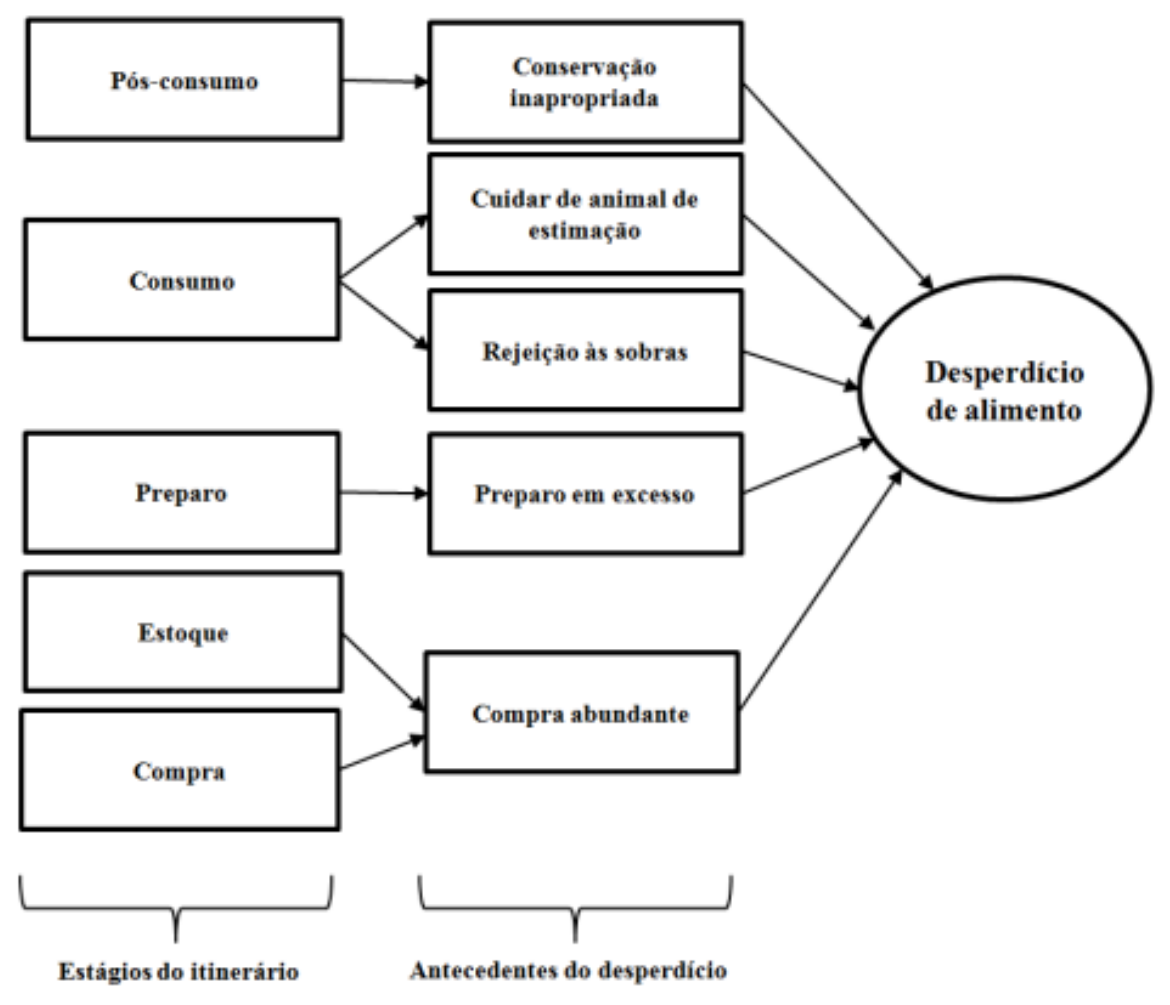

Fonte: Porpino (2018, p. 91).

A valorização da fartura é uma característica da cultura latina e famílias brasileiras de classe média apreciam a popularmente conhecida "despesa do mês", ou seja, idas ao supermercado para compras em grande volume e com estocagem desses produtos. Associado a isso está o preparo em excesso (gosto por mesas fartas durante as refeições) e o descarte de sobras (apreço por alimentos frescos). Os alimentos mais desperdiçados são principalmente as sobras de arroz e feijão e em menor quantidade carnes, já que são mais caras (PORPINO, 2018). Entretanto, as pesquisas citadas anteriormente possuem dados provenientes de análises com a classe média baixa. Populações que vivem em extrema pobreza e são base dos dados da FAO sobre fome não se enquadram nesse cenário.

\section{ANÁLISE DO NORDESTE BRASILEIRO}

Em 2014 o Brasil conseguiu atingir melhorias em seus números relacionados à desnutrição, o que lhe garantiu a saída do Mapa da Fome elaborado pela FAO. O período entre 2004 e 2014 foi marcado por 26,5 milhões de brasileiros deixando a pobreza. Esses dados são associados ao recente relatório divulgado pela FAO, O estado da segurança alimentar e da nutrição no mundo, no qual é observado uma queda nos índices de fome no Brasil. Entre 2004-2006 esse número representava 
4,6\% da população total, enquanto entre 2016-2018 esse índice caiu para 2,5\%, representando uma queda de 8,6 milhões de brasileiros que passavam fome para 5 milhões (FAO, 2019, p.95). Entretanto, apesar da queda representar uma melhora em $42 \%$, não houve avanços significativos nesse quesito desde 2010.

Os dados fornecidos pelo IBGE em sua última pesquisa realizada em 2013 demonstram como os índices brasileiros estão longes do ideal. 52 milhões de pessoas sofrem em algum grau com a insegurança alimentar, dos quais 23 milhões estão concentrados na região nordestina, um valor equivalente a $41,9 \%$ da população dessa região, sendo que mais de 3 milhões vivem em situação grave de insegurança alimentar, correspondente a um cenário de privação de alimentos, podendo chegar à sua expressão mais grave, a fome (IBGE, 2013, s.p.).

Contrariando os dados sobre a insegurança alimentar, é importante frisar que o Brasil possui a soja como o produto mais exportado pelo país, correspondendo a $12 \%$ das exportações e o milho na $5^{\text {a }}$ posição correspondendo a $3,2 \%$. Curiosamente apenas $6 \%$ da soja plantada no mundo, de acordo com o Departamento de Agricultura dos Estados Unidos (USDA), é direcionada para o consumo humano, pois sua principal função é a alimentação de animais para o abate(CARNEIRO, BORTOLIN, 2018, s.p.). No Brasil 51\% da área total agricultável é direcionada para soja e cada vez mais áreas são demandadas para esse plantio devido a indústria da carne. Se grande parte dessa área fosse voltada para a alimentação de sua própria população, os dados sobre a fome no Brasil tenderiam a desaparecer. Como essa realidade parece estar longe de ser alcançada devido ao crescente consumo de carne e ao anseio dos grandes proprietários na maximização dos lucros, é possível focar na produção que já é direcionada aos brasileiros e tudo aquilo que a ronda, como o desperdício de alimentos.

Os dados apresentados pela Embrapa sobre o desperdício foram coletados a partir de famílias de classe média baixa em sua maioria e em todo território nacional, não podendo ser relacionados com os dados do IBGE sobre os milhões de brasileiros que sofrem com a fome e que se concentram primordialmente no nordeste. A coleta de informações sobre o desperdício e perda de alimentos ainda é fraca, gerando valores imprecisos e de forma genérica, já que não há uma metodologia padrão que possa avaliar de maneira confiável esses dados. Entretanto, é possível fazer uma análise sobre como o desperdício impacta nas populações mais pobres e no desenvolvimento econômico de regiões de baixa renda. De acordo com o Portal Embrapa "se um terço do alimento produzido for para o lixo, por exemplo, consequentemente um terço dos recursos hídricos, energéticos, e financeiros empregados na produção também serão desperdiçados”. O desperdício de alimentos também gera impactos sobre o meio ambiente, afetando tanto a biodiversidade quanto o clima, já que serão necessários mais insumos e áreas férteis para a produção de um alimento que 
não será efetivamente consumido. Com a diminuição do desperdício, haveria menos pressão sobre as terras agricultáveis e a biodiversidade seria menos comprometida.

A falta de dados dificulta a realização da relação entre a fome e o desperdício de alimentos, principalmente em regiões mais atingidas como o Nordeste. Entretanto, é possível debater sobre os meios de descarte dos alimentos no meio varejista. Uma política adotada pelo estado do Ceará vinculada com o Programa Mais Nutrição tem como objetivo interligar a garantia da segurança alimentar de crianças e adolescentes cearenses e a diminuição do desperdício de frutas, verduras e legumes não comercializados pela Central de Abastecimento do Ceará (Ceasa). A iniciativa pretende beneficiar cerca de 10.400 jovens atendidos por 91 entidades cearenses para que estes possam receber sopas e polpas de frutas produzidas por meio de alimentos doados.

É estimado que no mundo são desperdiçados o equivalente a 1,6 bilhão de toneladas anuais, avaliado em US\$1,2 trilhão (BCG, 2018) e apenas a América Latina é responsável pelo desperdício de 127 milhões de toneladas de alimentos ao ano, o que corresponde a 97 bilhões de dólares (FAO, 2016). Como o controle das perdas de alimentos nos primeiros níveis como plantação, pós-colheita e transporte são difíceis, as tentativas de interligar o desperdício com a fome devem rondar as fases finais do consumo, principalmente do varejo. Os alimentos próprios para o consumo que não forem comercializados podem ser doados para projetos como a Rede Brasileira de Bancos de Alimentos, uma iniciativa envolvendo o âmbito público, privado e da sociedade civil na qual há a captação, recepção, triagem e distribuição gratuita de alimentos provindos de doações, que são direcionadas a instituições socioassistenciais, educacionais, de saúde, entre outras, que estejam cadastradas no programa.

Alimentos que não estão mais em condições de consumo humano podem ainda ser reutilizados para a melhoria da segurança alimentar. Grande parte da produção agrícola brasileira, voltada para plantação de soja, poderia sofrer modificações caso os animais em vez de consumirem ração oriunda desse plantio, consumissem as sobras do que não é comercializado pelo varejo. $\mathrm{O}$ redirecionamento desses alimentos disponibilizaria as áreas agricultáveis para policulturas e que não dependessem de grandes latifundiários. Caso os alimentos não pudessem ser consumidos pelos animais, a compostagem poderia ser uma solução, diminuindo a dependência de pequenos produtores de fertilizantes vendidos por grandes empresas. A compostagem, apesar de não diminuir o número do desperdício em si, traz uma utilização para o produto, que não pode ser consumido, mais sustentável do que apenas o seu descarte. 


\section{MEDIDAS DO GOVERNO}

As medidas adotadas pelo governo para a diminuição da fome recebemmaior atenção da mídia e da população em geral, como a iniciativa do Bolsa Família, mas medidas que envolvem a questão do desperdício de alimentos recebem menos repercussão. Além das medidas adotadas pela Rede Brasileira de Bancos de Alimentos há, segundo o Boletim Legislativo "Desperdício de Alimentos: questões socioambientais, econômicas e regulatórias" e a Embrapa, alguns projetos de lei do Senado sobre o tema em tramitação. O primeiro deles é o PLS n ${ }^{\circ}$ 503, de 2015, com a proposta de impulsionar empresas a doarem alimentos, seja através de reduções tributárias sobre os valores doados ou pela penalização de empresas que preferirem vender produtos perto do prazo de validade em vez de doá-los no tempo hábil.

O segundo projeto, PLS n ${ }^{\circ}$ 672, de 2015, dispõe sobre a redução do desperdício de alimentos por estabelecimentos tais como indústrias, supermercados, mercados, restaurantes, cozinhas, feiras, sacolões e assemelhados, com mais de 200 metros quadrados de área construída, os quais deverão estabelecer vínculos com organizações de natureza social dedicadas à coleta e distribuição de alimentos e refeições ou com empresas dedicadas à produção de ração animal e compostagem, isentando esses estabelecimentos de responsabilidade civil e penal, resultante do dano ocasionado ao beneficiário, pelo consumo do bem doado, desde que não caracterize dolo e negligência.

O PLS no 675, de 2015, por sua vez, estabelece uma Política Nacional de Combate ao Desperdício de Alimentos, apresentando objetivos e instrumentos para sua implantação, e permitindo a doação de alimentos, conforme dispõe o regulamento. E por fim o

PLS $n^{\circ} 738$, de 2015 que dispõe sobre o combate ao desperdício de alimentos voluntariamente descartados; prazos de validade para venda e para consumo seguro; campanhas educativas do consumidor; e sobre estabelecimentos de comercialização de alimentos por atacado ou varejo cuja receita bruta média anual seja igual ou superior à das empresas de pequeno porte, que poderão doar a entidades beneficentes de assistência social, gêneros alimentícios industrializados, preparados ou in natura, dentro do prazo de validade para venda que, por qualquer razão, tenham perdido sua condição de comercialização, ou fora deste prazo, desde que ainda estejam em condições e no prazo de consumo seguro. O PLS altera vários dispositivos legais, entre eles o Decreto-Lei $n^{\circ}$ 986, de 21 de outubro de 1969, que institui normas básicas sobre alimentos, a fim de prever a doação e a reutilização de alimentos no Brasil (EMBRAPA, s.p.).

Outros inúmeros projetos de lei propostos por deputados em âmbito estadual e vereadores em municipal tramitam nas câmaras com o objetivo de diminuir os índices de desperdício e de certa forma conseguir contribuir para a diminuição da fome. Leis como essas são essenciais para regulamentar as possíveis doações de alimentos, já que estes são em grande parte perecíveis e podem prejudicar aqueles que o recebem sem o devido cuidado. 


\section{CONCLUSÃO}

Os poucos dados fornecidos pelos governos sobre a questão do desperdício de alimentos demonstram a necessidade do investimento nessa área, principalmente quando envolvem a questão da fome tão crítica em regiões como o Nordeste. Não foi possível estabelecer uma relação direta entre os níveis de desperdício e as populações carentes que sofrem com a insegurança alimentar apesar da produção de alimentos no Brasil ser suficiente para abastecer sua população. Seguindo o pensamento de Shutter de que a questão da fome se trata de uma má distribuição de alimentos e não a falta deles em si, o desperdício potencializaria esse argumento devido às milhões de toneladas desperdiçadas por ano.

A insegurança alimentar que assola o Nordeste pode ser vinculada ao direcionamento da agricultura para o plantio de soja e consequentemente a produção de carne. O cultivo de soja é caracterizado pela monocultura latifundiária indo em confronto com a policultura do pequeno produtor, queé o responsável pela alimentação das populações brasileiras. A priorização da indústria da carne marginaliza mais ainda as populações pobres. Os mais de 3 milhões de nordestinos que vivem em situação grave de insegurança alimentar não possuem capital nem meios para consumir carne, sua alimentação se baseia em arroz e feijão, ou seja, as terras cada mais vez mais adquiridas para a produção de proteína animal são retiradas das mãos daqueles que não possuem dinheiro suficiente para consumi-la. O Nordeste ainda é a região que mais sofre com a questão da seca, uma realidade que ainda persiste devido a falta de investimentos na área. Com todo o capital indo em direção aos latifúndios, as comunidades sertanejas se tornam dependentes dos ciclos naturais da região para o plantio de seus alimentos, gerando ondas de fome de acordo com a falta ou não de chuvas.

A realidade enfrentada por essas populações poderia ser amenizada com o direcionamento correto de alimentos, diminuindo assim os números de desperdício, como as iniciativas tomadas pelo governo do Ceará para vincular os produtos doados por varejistas e encaminhá-los a instituições que forneçam alimentação às populações que necessitam. Para que tais iniciativas possam ocorrer com um acompanhamento de dados mais apurado, é necessário investimentos na área para estabelecer modelos semelhantes de análise de informações, já que as estimativas são influenciadas por inúmeros aspectos, tais como época do ano (período seco ou das chuvas), tipo de produto avaliado, o nível tecnológico do produtor, possível aproveitamento de subprodutos, uso na alimentação animal, compostagem, entre outros. O desperdício de alimentos ocasiona gastos hídricos, financeiros e energéticos que poderiam ser evitados. Parcerias entre público-privado em campanhas e projetos são uma forma de diminuir esses gastos perdidos além de proporcionar alguma melhora em certo nível às populações que sofrem com a insegurança alimentar diariamente. 


\section{REFERÊNCIAS BIBLIOGRÁFICAS}

BCG (2018). Tackling the 1.6-Billion ton food loss and waste crisis. Boston Consulting Group. Disponível em https://www.bcg.com/pt-br/ publications/2018/tackling-1.6-billion-ton-foodloss-and-waste-crisis.aspx.

BORTOLIN, Nelson; CARNEIRO, Gustavo. O Brasil é Soja. Folha de Londrina. 16 de jun. de 2018. Disponível em: https://folhadelondrina-1.atavist.com/brasil-soja. Acesso em: 15 de maio de 2020.

CRISPIM, Marristela. Ceará deve ganhar Plano Estadual de Combate às Perdas e ao Desperdício de Alimentos. Eco Nordeste. 29 de jun. de 2019. Disponível em: http://agenciaeconordeste.com.br/ceara-deve-ganhar-plano-estadual-de-combate-as-perdas-e-ao-des perdicio-de-alimentos/. Acesso em: 15 de maio de 2020.

EMBRAPA. Perdas e desperdício de alimentos. Perguntas e Respostas. Disponível em: https://www.embrapa.br/tema-perdas-e-desperdicio-de-alimentos/perguntas-e-respostas. Acesso em: 15 de maio de 2020.

FAO. Food losses and waste in Latin America and Caribbean. 2016. Disponível em: http://www.fao.org/3/a-i5504e.pdf

FAO. Global food losses and food waste - Extent, causes and prevention. 2011. Roma, FAO.

FAO. How to Feed the World in 2050. 2009. Roma, FAO.

FAO, IFAD, UNICEF, WFP, WHO. The State of Food Security and Nutrition in the World 2019. 2019. Safeguarding against economic slowdowns and downturns. Roma, FAO.

FAO, IFAD, UNICEF, WFP, WHO. The State of Food Security and Nutrition in the World 2018. 2018. Building climate resilience for food security and nutrition. Roma, FAO.

IBGE - INSTITUTO BRASILEIRO DE GEOGRAFIA. População residente, por situação de segurança alimentar existente no domicílio e tipo de insegurança alimentar, segundo o sexo, os grupos de idade, a cor ou raça, a situação do domicílio e as classes de rendimento mensal domiciliar per capita - Região Nordeste. 2013. Rio de Janeiro.

LENZ, Maria Heloísa. A Teoria da Renda da Terra: Ricardo e Malthus. Ensaios FEE, v. 6, n. 1, p. 81-104, 1985.

MINISTÉRIO DA INDÚSTRIA, COMÉRCIO EXTERIOR E SERVIÇOS (2019). Visão Geral dos Produtos Exportados. Disponível em: http://comexstat.mdic.gov.br/pt/comex-vis. Acesso em: 15 de maio de 2020.

O PORTAL DO BRASIL. Aderir à Rede Brasileira de Banco de Alimentos (RBBA). Disponível em: https://www.gov.br/pt-br/servicos/participar-da-rede-brasileira-de-banco-de-alimentos. Acesso em 15 de maio de 2020.

PORPINO, G.; LOURENÇO, C. E.; ARAÚJO, C.M.; BASTOS, A. Intercâmbio Brasil - União Europeia sobre desperdício de alimentos. Relatório final de pesquisa. Brasília: Diálogos Setoriais União Europeia - Brasil, 2018.

PORPINO, Gustavo. 5 Quais os porquês do desperdício de alimentos entre consumidores? Compreendendo o comportamento do consumidor para delinear soluções. 2018. 
CANOSO, R. O COMBATE À FOME E AO DESPERDíCIO DE ALIMENTOS.

DOI: 10.36942/IANDE.V5I1.262

SHUTTER, Oliver de. Report of the Special Rapporteur on the right to food. Relatório. 2014. 